\title{
Index Decomposition Analysis on Factors Affecting Energy-Related Carbon Dioxide Emissions from Residential Consumption in Beijing
}

\author{
Fengyan Fan ${ }^{1,2}$ and Yalin Lei ${ }^{3,4}$ \\ ${ }^{1}$ Research Center for Strategy of Global Mineral Resources, Chinese Academy of Geological Sciences, Beijing 100037, China \\ ${ }^{2}$ Institute of Mineral Resources, Chinese Academy of Geological Sciences, Beijing 100037, China \\ ${ }^{3}$ School of Humanities and Economic Management, China University of Geosciences, Beijing 100083, China \\ ${ }^{4}$ Key Laboratory of Carrying Capacity Assessment for Resource and Environment, Ministry of Land and Resource, \\ Beijing 100083, China \\ Correspondence should be addressed to Yalin Lei; leiyalin@cugb.edu.cn
}

Received 14 September 2016; Revised 25 November 2016; Accepted 8 December 2016; Published 19 January 2017

Academic Editor: Jean-Pierre Corriou

Copyright (c) 2017 Fengyan Fan and Yalin Lei. This is an open access article distributed under the Creative Commons Attribution License, which permits unrestricted use, distribution, and reproduction in any medium, provided the original work is properly cited.

\begin{abstract}
Beijing's residential $\mathrm{CO}_{2}$ emissions have become the main growth point of $\mathrm{CO}_{2}$ emissions. However, the impact factors of the direct energy-related $\mathrm{CO}_{2}$ emissions from residents in Beijing have not been previously evaluated. This paper accessed the key factors that affect the residents' $\mathrm{CO}_{2}$ emissions in Beijing from 1995 to 2015, using a newly built decomposition model with generalized Fisher index (GFI) and M-P model. The results were compared between urban and rural areas. Urban residential $\mathrm{CO}_{2}$ emissions did not change during 1995-1999 but then grew rapidly after 1999, while rural residential $\mathrm{CO}_{2}$ emissions fluctuated during the studied period. Increased per capita income is the most important pulling factor for the growth of residential $\mathrm{CO}_{2}$ emissions, while energy consumption intensity is a decisive factor in inhibiting residential $\mathrm{CO}_{2}$ emissions. Population size plays a pulling role in the growth of residential $\mathrm{CO}_{2}$ emissions. Energy structure exerts a role in inhibiting residential $\mathrm{CO}_{2}$ emissions, and its inhibition effect is stronger for urban residents. Average consumption propensity inhibits urban residential $\mathrm{CO}_{2}$ emissions but has little effect on rural residential $\mathrm{CO}_{2}$ emissions. The population migration from rural to urban areas in the urbanization process increases residential $\mathrm{CO}_{2}$ emissions. To reduce residential $\mathrm{CO}_{2}$ emissions, several recommendations have been proposed.
\end{abstract}

\section{Introduction}

Global warming has become the focus all over the world. It not only causes extreme weather disasters but also affects the sustainable development of social economies. An assessment report by the Intergovernmental Panel on Climate Change (IPCC) noted that increased carbon dioxide $\left(\mathrm{CO}_{2}\right)$ emissions caused by fossil energy consumption are a major cause of global climate change. Fossil-based energy is mainly supplied by the production sector; therefore, most scholars tend to research on $\mathrm{CO}_{2}$ emissions in industrial production. However, with economic development and the improvement of living standards, residents' consumption preferences have changed, leading to a rapid growth of energy consumption.
The data from "China Energy Statistical Yearbook" show that Chinese household energy consumption (calculated according to the method of electricity generation coal consumption) in 2014 accounted for $11.1 \%$ of total energy consumption. Therefore, conserving energy in residential consumption has become an important aspect of energy saving and emissions reduction.

As the main body of terminal product and service consumption, residential energy consumption and its $\mathrm{CO}_{2}$ emissions have attracted increased attention from the societal and scientific communities. Chitnis and Hunt [1] estimated the transportation and residential energy expenditure equations in the UK between 1964 and 2009 by adopting the structural time-series model. These estimated equations show that $\mathrm{CO}_{2}$ 
emissions from transportation and residential expenditures will not fall by $29 \%$ (or $40 \%$ ) in 2020 compared to 1990 ; that is, $\mathrm{UK} \mathrm{CO}_{2}$ reduction target cannot be achieved. S. Lee and B. Lee [2] adopted multilevel structural equation modeling (SEM) to examine the paths by which the form of an urban area affects residents' $\mathrm{CO}_{2}$ emissions in the US 125 largest cities. The results show that doubling populationweighted density reduced $\mathrm{CO}_{2}$ emissions from family travel and living energy consumption by $48 \%$ and $35 \%$, respectively. A concentrated population and the presence of polycentric structures only have modest effects. Sharaai et al. [3] used the same method to identify the influence of household number, household total incomes, electricity consumption, liquefied petroleum gas, and transportation fuel on household carbon emissions (HCE) in Penang. Sharaai's results demonstrate that total household income, electricity consumption, and transportation fuel were significantly positively correlated with the amount of HCE. Das and Paul [4] used input-output analysis to estimate the direct and indirect household $\mathrm{CO}_{2}$ emissions in 1993-1994, 1998-1999, 2003-2004, and 20062007, using complete decomposition to analyze the factors affecting $\mathrm{CO}_{2}$ emissions. The results indicate that activity, structure, and population effects are the main reasons of increased household $\mathrm{CO}_{2}$ emissions. Kerkhof et al. [5] quantified the determinants and distribution of household $\mathrm{CO}_{2}$ emissions in Netherlands (2000), UK (1998), Sweden (2002), and Norway (1997). The results suggest that $\mathrm{CO}_{2}$ emission intensities and country characteristics, such as energy supply, population density, and the availability of district heating, affect the change of household $\mathrm{CO}_{2}$ emissions between and within countries. Miehe et al. [6] adopted a multiregion input-output hybrid Life Cycle Assessment (LCA) approach to examine the driving factors such as location, income, and size of household carbon footprint in Germany. Castellucci et al. [7] explored the relationship between income distribution and household direct emissions in Italy.

In recent years, China has entered an important stage of rapid economic development and residential consumption growth. With increasing prosperity and the advance of urbanization, $\mathrm{CO}_{2}$ emissions from residential consumption will grow. Under such background, research on the residential $\mathrm{CO}_{2}$ emissions and its influencing factors in China has been paid more and more attention. Based on the application of a Consumer Lifestyle Approach (CLA), Wei et al. [8] quantified the direct and indirect impact of lifestyle of urban and rural residents on China's energy-related $\mathrm{CO}_{2}$ emissions during the period 1999-2002. Huang and Jiang [9] calculated the direct and indirect $\mathrm{CO}_{2}$ emissions in China and analyzed the dynamic characteristics of household $\mathrm{CO}_{2}$ emissions. The results show that the residential $\mathrm{CO}_{2}$ emissions have been increased year by year. The consumption of "food," "residences," and "transportation and communication" are the main source of indirect $\mathrm{CO}_{2}$ emissions. Dai et al. [10] explored the impact of consumption patterns on carbon dioxide $\left(\mathrm{CO}_{2}\right)$ emissions in two baseline scenarios over the period 2005-2050; household expenditure shifts from material products and transport to service-oriented goods is benefit for the carbon emission conservation. Wang and Ru [11], Wang and Yang [12], Liu et al. [13], Li [14], Wang et al. [15],
Huang and Jiang [9], Zhu et al. [16], Li et al. [17], Wang and Yang [18], Wu et al. [19], Wang et al. [20], and Wu et al. [21] studied the affecting factors of $\mathrm{CO}_{2}$ emissions in China and different regions. Although their methods differ, scholars universally argue that higher consumption levels, population growth, urban expansion, residential consumption structures, and economic growth play roles in increasing $\mathrm{CO}_{2}$ emissions. Further, scholars agree that, to a certain extent, rising energy prices and a decline in energy intensity or carbon intensity inhibit the growth of residential energy consumption and $\mathrm{CO}_{2}$ emissions. Throughout the literature, the degree of influence attributed to different factors varies. Scholars disagree about the effect that the size and directionality of energy structures have on residential $\mathrm{CO}_{2}$ emissions. Wang and $\mathrm{Ru}$ [11] and Peng and Zhang [22] show that changes in energy consumption structures promote the reduction of $\mathrm{CO}_{2}$ emissions from residential energy consumption. Conversely, Wang et al. [15] note that the changes in energy consumption structures promote the growth of residential $\mathrm{CO}_{2}$ emissions. Wang and Yang [12], $\mathrm{Li}$ [14], and Qu et al. [23] argue that the contributions of various factors differ between urban and rural areas.

In the study of residential $\mathrm{CO}_{2}$ emissions, most scholars focus on the overall national or regional situation of direct and indirect $\mathrm{CO}_{2}$ emissions caused by residential energy consumption [24-28], the source structure of residential $\mathrm{CO}_{2}$ emissions $[8,9]$, the impact of residential lifestyle $[1,10,29-$ $31]$, income level $[5,32,33]$, population $[34,35]$, and other factors on $\mathrm{CO}_{2}$ emissions. Although the research on $\mathrm{CO}_{2}$ emissions is more and more in-depth, there are still two main defects. The first defect is that the existing literature pays more attention to the indirect $\mathrm{CO}_{2}$ emissions. However, the indirect $\mathrm{CO}_{2}$ emissions are from other sectors' direct $\mathrm{CO}_{2}$ emissions. It is clear that the research on the residents' direct $\mathrm{CO}_{2}$ emissions is not enough. The second defect is that the current studies mainly measure and assess the direct and indirect energy-related $\mathrm{CO}_{2}$ emissions, and quantitative analysis on the impact factors of direct of $\mathrm{CO}_{2}$ emissions from residential consumption is insufficient.

From the view of research methods, the analysis methods of factors affecting $\mathrm{CO}_{2}$ emissions are mainly divided into two categories: one is the decomposition method and the other one is the econometric method. Compared with the econometric technique, the decomposition method better respects the original data and can more accurately reflect the actual trends of $\mathrm{CO}_{2}$ emissions. The decomposition method mainly includes two categories: index decomposition analysis (IDA) and structural decomposition analysis (SDA). SDA relies on input-output (IO) tables which are only updated every few years in most countries. IDA uses annual statistics which allows the analysis to be conducted in a time-series form [36], and it requires less data and facilitates comparative and empirical research and has been favored by scholars.

Most studies use a simple dataset which is single dimensional; a finer level may lead to a higher degree of cancellation among subcategory effects [37]. To avoid the limitation, multilevel index decomposition analysis has been proposed $[38,39]$ and developed more recently. For instance, Liu et al. [40] attempt to uncover China's greenhouse gas emission 
changes at both regional and sectoral dimensions. Petrick [41] quantified the driving forces behind Germany's $\mathrm{CO}_{2}$ emission changes at industry subsector and plant levels. Actually, Ang et al. [42] once conducted a number of tests between the generalized Fisher index and other five common index decomposition methods (see Table 1 in Ang et al. [42] for details). The results suggest the generalized Fisher index is a better method for performing decomposition due to its good decomposition characteristics without the decomposition residuals. Compared with other index decomposition methods, the result of the generalized Fisher index is more accurate. In another study, $\mathrm{Xu}$ and Ang [43] introduced two multilevel decomposition models and studied their features. One is the M-P model, which is very similar to the conventional single-level model in calculation procedure; the other one is $\mathrm{M}-\mathrm{H}$ model, which adopts a stepwise decomposition procedure. Meanwhile, Xu and Ang [43] also pointed out that the Fisher ideal index cannot be transformed to meet the requirements of $\mathrm{M}-\mathrm{H}$ model. Therefore, we combined the generalized Fisher index analysis with the M-P model and divided residential $\mathrm{CO}_{2}$ emissions in Beijing into two aspects of urban and rural areas and conducted a comparative analysis.

Beijing is one of the biggest cities with the highest population, most economic activity, and highest energy consumption in China. According to the "reference algorithm" in the "Guidelines for National Greenhouse Gas Inventories" [44], Beijing's residential $\mathrm{CO}_{2}$ emissions accounted for $25.4 \%$ of $\mathrm{CO}_{2}$ emissions from terminal energy consumption in 2015. They have become the main growth point of $\mathrm{CO}_{2}$ emissions, exceeding the industrial and transportation sectors. An analysis of the factors influencing $\mathrm{CO}_{2}$ emissions from residential consumption in Beijing has broad significance. The results of this research have relevance to low-carbon economic development, not only for other regions of China but also for certain metropolitan areas worldwide. Further, they can guide residents' efforts to live within reasonable consumption patterns. Reviewing the existing literature, it is apparent that scholars have been devoted to some problems on $\mathrm{CO}_{2}$ emissions from residential consumption using different countries and regions as their research objects. However, due to lifestyle diversification and the influence of many natural and cultural factors on residential $\mathrm{CO}_{2}$ emissions, the conclusions from other regions cannot fully explain the situation in Beijing. The analysis on the impact factors of the direct energy-related $\mathrm{CO}_{2}$ emissions from residents in Beijing has not been involved. Additionally, China is a typical urban-rural dual structure; there is a significant gap between urban and rural areas (for instance, residence types and residential consumption are different and lifetime $\mathrm{CO}_{2}$ emissions also exhibit different characteristics). Most of the existing research primarily focuses on the overall situation of residential energy consumption and related $\mathrm{CO}_{2}$ emissions. Research work on comparative analysis of $\mathrm{CO}_{2}$ emissions from urban and rural residents is insufficient. Therefore, this paper built a multivariate decomposition model with generalized Fisher index (GFI) and M-P model to evaluate key factors in urban and rural residential energyrelated $\mathrm{CO}_{2}$ emissions between 1995 and 2015 in Beijing.
The objectives of the paper are analysis on the change trend of residential $\mathrm{CO}_{2}$ emissions in Beijing and identification, quantification, explanation, and comparative analysis of the driving forces behind the change between urban and rural areas. Our findings help to understand how the driving forces affect changes in residential $\mathrm{CO}_{2}$ emissions, providing data for decision-making of low-carbon development in Beijing.

\section{Methodology}

2.1. Calculation of Residential Energy-Related $\mathrm{CO}_{2}$ Emissions. Since there is no direct monitoring data on $\mathrm{CO}_{2}$ emissions, $\mathrm{CO}_{2}$ emissions are mainly estimated from the data which can be collected. By comparison, this paper uses the method provided by IPCC to calculate residential $\mathrm{CO}_{2}$ emissions in Beijing. Specific expression is

$$
\begin{aligned}
\mathrm{CO}_{2} & =\sum_{i} \mathrm{CO}_{2, i}=\sum_{i} E_{i} \times \delta_{i} \\
& =\sum_{i} E_{i} \times \mathrm{NCV}_{i} \times \mathrm{CEF}_{i} \times \mathrm{COF}_{i} \times \frac{44}{12},
\end{aligned}
$$

where $\mathrm{CO}_{2}$ is the estimated $\mathrm{CO}_{2}$ emissions (million tons); $i$ represents the energy type; $E$ is the energy consumption (million tons or billion cubic meters); NCV is the net calorific value $\left(\mathrm{kJ} / \mathrm{kg}\right.$ or $\left.\mathrm{kJ} / \mathrm{m}^{3}\right)$; CEF is the carbon emission factor, which represents the carbon level per unit calorific value $\left(\mathrm{kg} / 10^{6} \mathrm{~kJ}\right)$; and COF is the carbon oxidation factor reflecting the carbon oxidation rate during energy combustion.

2.2. The Multilevel-Parallel (M-P) Model. Considering the daily living energy consumption of residents, consumer spending is an important factor in generating residential $\mathrm{CO}_{2}$ emissions [11]; and in the process of urbanization, there are great differences between the energy consumption structures and energy consumption levels of urban and rural residents. Therefore, urban and rural population structures and changes in energy structure will affect residential $\mathrm{CO}_{2}$ emissions. Subsequent research shows that residential income and energy intensity have certain effects on residential $\mathrm{CO}_{2}$ emissions $[12,13]$. We divide the residents into two categories: urban and rural residents. Combined with the characteristics of residential energy consumption, we decompose the residential $\mathrm{CO}_{2}$ emissions as follows:

$$
C_{i j}=\sum_{i} \sum_{j} C_{i j}=\sum_{i} \sum_{j} \frac{C_{i j}}{E_{i j}} \frac{E_{i j}}{E_{i}} \frac{E_{i}}{L_{i}} \frac{L_{i}}{Q_{i}} \frac{Q_{i}}{P_{i}} \frac{P_{i}}{P} P,
$$

where $i$ is the type of residents ( $i=1$ represents the urban residents; $i=2$ represents the rural residents); $j$ is the type of energy consumed by residents; $C_{i j}$ represents the $\mathrm{CO}_{2}$ emissions of energy $j$ by urban or rural residents. $E_{i j}$ is consumption of energy $j$ by urban or rural residents, which is expressed by standard coal. $E_{i}$ is the total energy consumption of urban or rural residents; $L_{i}$ is the consumption expenditure of urban or rural residents; $Q_{i}$ is the disposable income of urban or rural residents; $P_{i}$ is the population of the urban or rural area; $P$ is the total population of Beijing. 
2.3. Generalized Fisher Index Decomposition. The Fisher index decomposition method was put forward by Fisher for the first time [42]. The expression of the basic model is shown as follows:

$$
V=\sum_{i} V_{i}=\sum_{i} X_{1 i} X_{2 i}
$$

where $V$ represents an indicator to be decomposed, $i$ denotes the subcategory of the indicator, and $X_{1 i}$ and $X_{2 i}$ represent the decomposed affecting factors. The variation of $V$ from year 0 to year $T$ can be decomposed into $D_{X_{1}}$ and $D_{X_{2}}$ :

$$
V=\frac{V^{T}}{V^{0}}=\frac{\sum_{i} X_{1 i}^{T} X_{2 i}^{T}}{\sum_{i} X_{1 i}^{0} X_{2 i}^{0}}=D_{X_{1}} \cdot D_{X_{2}}
$$

In accordance with the Fisher index formula, it can be obtained that

$$
\begin{aligned}
& D_{X_{1}}=\left[\frac{\sum_{i} X_{1 i}^{T} X_{2 i}^{0}}{\sum_{i} X_{1 i}^{0} X_{2 i}^{0}} \cdot \frac{\sum_{i} X_{1 i}^{T} X_{2 i}^{T}}{\sum_{i} X_{1 i}^{0} X_{2 i}^{T}}\right]^{1 / 2} \\
& D_{X_{2}}=\left[\frac{\sum_{i} X_{1 i}^{0} X_{2 i}^{T}}{\sum_{i} X_{1 i}^{0} X_{2 i}^{0}} \cdot \frac{\sum_{i} X_{1 i}^{T} X_{2 i}^{T}}{\sum_{i} X_{1 i}^{T} X_{2 i}^{0}}\right]^{1 / 2} .
\end{aligned}
$$

In empirical studies, two factors are insufficient for solving problems. Ang et al. [42] extended the two factors to multiple factors and proposed the generalized Fisher index. The implementation process is as follows.

$V$ is the aggregate indicator, composed of $n$ elements:

$$
V=\sum_{i} X_{1} X_{2} \cdots X_{n}
$$

Define the set $N=\{1,2, \ldots, n\}$ in which the cardinality of $N$ is $n$. S is a subset of $N$, for which the cardinality is $s^{\prime}$. Define a function $V(S)=\sum\left(\prod_{l \in S} X_{l}^{T} \prod_{m \in N \backslash S} X_{m}^{0}\right)$ and $V(\Phi)=$ $\sum\left(\prod_{m \in N} X_{m}^{o}\right)$, where $\Phi$ is a null set. The superscripts $T$ and 0 represent the current year and the base year, respectively. In accordance with the "geometric average" principle, $V^{T} / V^{0}$ is divided into $n$ parts, and the decomposition results of factor $X_{j}(j=1,2, \ldots, n)$ can be given as follows:

$$
\begin{aligned}
D_{X_{j}} & =\prod_{\substack{S \subset N \\
j \in S}}\left[\frac{V(S)}{V(S \backslash\{j\})}\right]^{(1 / n) \cdot\left(1 /\left(\begin{array}{c}
n-1 \\
s^{\prime}-1
\end{array}\right)\right)} \\
& =\prod_{\substack{S \subset N \\
j \in S}}\left[\frac{V(S)}{V(S \backslash\{j\})}\right]^{\left(\left(s^{\prime}-1\right) !\left(n-s^{\prime}\right) !\right) / n !} .
\end{aligned}
$$

$D_{X_{j}}(j=1,2, \ldots, n)$ is the decomposition effect of factors with the generalized Fisher index method.

Based on the above method, (2) is defined as follows: energy-related $\mathrm{CO}_{2}$ emission coefficient $X_{1 i j}=C_{i j} / E_{i j}$, namely, $\mathrm{CO}_{2}$ emission coefficient of energy $j$ by $i$ resident, and energy structure $X_{2 i j}=E_{i j} / E_{i}$, namely, consumption proportion of energy $j$ by $i$ resident, accounted for the total energy consumption from $i$ resident; energy consumption intensity $X_{3 i}=E_{i} / L_{i}$ represents energy consumption per unit consumer expense from $i$ resident; average consumption propensity $X_{4 i}=L_{i} / Q_{i}$ represents the proportion of consumer expenses in $i$ th residential disposable income; per capita income $X_{5 i}=Q_{i} / P_{i}$ represents the per capita disposable income of $i$ resident; population structure $X_{6 i}=P_{i} / P$ represents the proportion of $i$ resident in total population; population size $X_{7 i}=P$ is the total population of Beijing. Thus, in this way, $\mathrm{CO}_{2}$ emissions can be decomposed as follows:

$$
\begin{aligned}
C_{i} & =\sum_{i} \sum_{j} C_{i j}=\sum_{i} \sum_{j} \frac{C_{i j}}{E_{i j}} \frac{E_{i j}}{E_{i}} \frac{E_{i}}{L_{i}} \frac{L_{i}}{Q_{i}} \frac{Q_{i}}{P_{i}} \frac{P_{i}}{P} P \\
& =\sum_{i} \sum_{j} X_{1 i j} X_{2 i j} X_{3 i} X_{4 i} X_{5 i} X_{6 i} X_{7 i} .
\end{aligned}
$$

Generally, except for heat and power, the $\mathrm{CO}_{2}$ emission coefficients of all types of energy are fixed; therefore, the factors affecting residential $\mathrm{CO}_{2}$ emissions in Beijing are mainly the energy structure, energy consumption intensity, average consumption propensity, per capita disposable income, population structure, and population size. The change of residential $\mathrm{CO}_{2}$ emissions can be decomposed as follows:

$$
\frac{C^{T}}{C^{0}}=D_{X_{1}} D_{X_{2}} D_{X_{3}} D_{X_{4}} D_{X_{5}} D_{X_{6}},
$$

where $C^{T}$ is the $\mathrm{CO}_{2}$ emissions in year $T ; C^{0}$ is the $\mathrm{CO}_{2}$ emissions in the base year; $D_{X_{1}}$ is the energy structure effect where $X_{1}$ is the product of the energy structure $\left(E_{i j} / E\right)$ and corresponding $\mathrm{CO}_{2}$ emission coefficients $\left(C_{i j} / E_{i j}\right), D_{X_{2}}$ is the energy consumption intensity effect, $D_{X_{3}}$ is the average consumption propensity effect, $D_{X_{4}}$ is the per capita disposable income effect, $D_{X_{5}}$ is the population structure effect, and $D_{X_{6}}$ is the population size effect. $D_{X_{1}}$ can be written as [45]

$$
\begin{aligned}
D_{X_{1}}= & {\left[\frac{\left.\sum_{i} X_{1 i}^{T} X_{2}^{0} X_{3}^{0} X_{4}^{0} X_{5}^{0} X_{6}^{0} X_{1 i}^{0} X_{2}^{0} X_{3}^{0} X_{4}^{0} X_{5}^{0} X_{6}^{0}\right]}{1 / 6}\right.} \\
. & {\left[\frac{\sum_{i} X_{1 i}^{T} X_{2}^{T} X_{3}^{0} X_{4}^{0} X_{5}^{0} X_{6}^{0}}{\sum_{i} X_{1 i}^{0} X_{2}^{T} X_{3}^{0} X_{4}^{0} X_{5}^{0} X_{6}^{0}} \cdot \frac{\sum_{i} X_{1 i}^{T} X_{2}^{0} X_{3}^{T} X_{4}^{0} X_{5}^{0} X_{6}^{0}}{\sum_{i} X_{1 i}^{0} X_{2}^{0} X_{3}^{T} X_{4}^{0} X_{5}^{0} X_{6}^{0}}\right.} \\
& \cdot \frac{\sum_{i} X_{1 i}^{T} X_{2}^{0} X_{3}^{0} X_{4}^{T} X_{5}^{0} X_{6}^{0}}{\sum_{i} X_{1 i}^{0} X_{2}^{0} X_{3}^{0} X_{4}^{T} X_{5}^{0} X_{6}^{0}} \cdot \frac{\sum_{i} X_{1 i}^{T} X_{2}^{0} X_{3}^{0} X_{4}^{0} X_{5}^{T} X_{6}^{0}}{\sum_{i} X_{1 i}^{0} X_{2}^{0} X_{3}^{0} X_{4}^{0} X_{5}^{T} X_{6}^{0}} \\
& \left.\cdot \frac{\sum_{i} X_{1 i}^{T} X_{2}^{0} X_{3}^{0} X_{4}^{0} X_{5}^{0} X_{6}^{T}}{\sum_{i} X_{1 i}^{0} X_{2}^{0} X_{3}^{0} X_{4}^{0} X_{5}^{0} X_{6}^{T}}\right] \\
& \cdot\left[\frac{\sum_{i} X_{1 i}^{T} X_{2}^{T} X_{3}^{T} X_{4}^{0} X_{5}^{0} X_{6}^{0}}{\sum_{i} X_{1 i}^{0} X_{2}^{T} X_{3}^{T} X_{4}^{0} X_{5}^{0} X_{6}^{0}} \cdot \frac{\sum_{i} X_{1 i}^{T} X_{2}^{T} X_{3}^{0} X_{4}^{T} X_{5}^{0} X_{6}^{0}}{\sum_{i} X_{1 i}^{0} X_{2}^{T} X_{3}^{0} X_{4}^{T} X_{5}^{0} X_{6}^{0}}\right. \\
& \cdot \frac{\sum_{i} X_{1 i}^{T} X_{2}^{T} X_{3}^{0} X_{4}^{0} X_{5}^{T} X_{6}^{0}}{\sum_{i} X_{1 i}^{0} X_{2}^{T} X_{3}^{0} X_{4}^{0} X_{5}^{T} X_{6}^{0}} \cdot \frac{\sum_{i} X_{1 i}^{T} X_{2}^{T} X_{3}^{0} X_{4}^{0} X_{5}^{0} X_{6}^{T}}{\sum_{i} X_{1 i}^{0} X_{2}^{T} X_{3}^{0} X_{4}^{0} X_{5}^{0} X_{6}^{T}}
\end{aligned}
$$




$$
\begin{aligned}
& \frac{\sum_{i} X_{1 i}^{T} X_{2}^{0} X_{3}^{T} X_{4}^{T} X_{5}^{0} X_{6}^{0}}{\sum_{i} X_{1 i}^{0} X_{2}^{0} X_{3}^{T} X_{4}^{T} X_{5}^{0} X_{6}^{0}} \cdot \frac{\sum_{i} X_{1 i}^{T} X_{2}^{0} X_{3}^{T} X_{4}^{0} X_{5}^{T} X_{6}^{0}}{\sum_{i} X_{1 i}^{0} X_{2}^{0} X_{3}^{T} X_{4}^{0} X_{5}^{T} X_{6}^{0}} \\
& \frac{\sum_{i} X_{1 i}^{T} X_{2}^{0} X_{3}^{T} X_{4}^{0} X_{5}^{0} X_{6}^{T}}{\sum_{i} X_{1 i}^{0} X_{2}^{0} X_{3}^{T} X_{4}^{0} X_{5}^{0} X_{6}^{T}} \cdot \frac{\sum_{i} X_{1 i}^{T} X_{2}^{0} X_{3}^{0} X_{4}^{T} X_{5}^{T} X_{6}^{0}}{\sum_{i} X_{1 i}^{0} X_{2}^{0} X_{3}^{0} X_{4}^{T} X_{5}^{T} X_{6}^{0}} \\
& \frac{\sum_{i} X_{1 i}^{T} X_{2}^{0} X_{3}^{0} X_{4}^{T} X_{5}^{0} X_{6}^{T}}{\sum_{i} X_{1 i}^{0} X_{2}^{0} X_{3}^{0} X_{4}^{T} X_{5}^{0} X_{6}^{T}} \\
& \left.\cdot \frac{\sum_{i} X_{1 i}^{T} X_{2}^{0} X_{3}^{0} X_{4}^{0} X_{5}^{T} X_{6}^{T}}{\sum_{i} X_{1 i}^{0} X_{2}^{0} X_{3}^{0} X_{4}^{0} X_{5}^{T} X_{6}^{T}}\right]^{1 / 60} \\
& \cdot\left[\frac{\sum_{i} X_{1 i}^{T} X_{2}^{T} X_{3}^{T} X_{4}^{T} X_{5}^{0} X_{6}^{0}}{\sum_{i} X_{1 i}^{0} X_{2}^{T} X_{3}^{T} X_{4}^{T} X_{5}^{0} X_{6}^{0}} \cdot \frac{\sum_{i} X_{1 i}^{T} X_{2}^{T} X_{3}^{T} X_{4}^{0} X_{5}^{T} X_{6}^{0}}{\sum_{i} X_{1 i}^{0} X_{2}^{T} X_{3}^{T} X_{4}^{0} X_{5}^{T} X_{6}^{0}}\right. \\
& \cdot \frac{\sum_{i} X_{1 i}^{T} X_{2}^{T} X_{3}^{T} X_{4}^{0} X_{5}^{0} X_{6}^{T}}{\sum_{i} X_{1 i}^{0} X_{2}^{T} X_{3}^{T} X_{4}^{0} X_{5}^{0} X_{6}^{T}} \cdot \frac{\sum_{i} X_{11}^{T} X_{2}^{T} X_{3}^{0} X_{4}^{T} X_{5}^{T} X_{6}^{0}}{\sum_{i} X_{1 i}^{0} X_{2}^{T} X_{3}^{0} X_{4}^{T} X_{5}^{T} X_{6}^{0}} \\
& \frac{\sum_{i} X_{1 i}^{T} X_{2}^{T} X_{3}^{0} X_{4}^{T} X_{5}^{0} X_{6}^{T}}{\sum_{i} X_{1 i}^{0} X_{2}^{T} X_{3}^{0} X_{4}^{T} X_{5}^{0} X_{6}^{T}} \cdot \frac{\sum_{i} X_{1 i}^{T} X_{2}^{T} X_{3}^{0} X_{4}^{0} X_{5}^{T} X_{6}^{T}}{\sum_{i} X_{1 i}^{0} X_{2}^{T} X_{3}^{0} X_{4}^{0} X_{5}^{T} X_{6}^{T}} \\
& \cdot \frac{\sum_{i} X_{1 i}^{T} X_{2}^{0} X_{3}^{T} X_{4}^{T} X_{5}^{T} X_{6}^{0}}{\sum_{i} X_{1 i}^{0} X_{2}^{0} X_{3}^{T} X_{4}^{T} X_{5}^{T} X_{6}^{0}} \cdot \frac{\sum_{i} X_{1}^{T} X_{2}^{0} X_{3}^{T} X_{4}^{T} X_{5}^{0} X_{6}^{T}}{\sum_{i} X_{1 i}^{0} X_{2}^{0} X_{3}^{T} X_{4}^{T} X_{5}^{0} X_{6}^{T}} \\
& \frac{\sum_{i} X_{1 i}^{T} X_{2}^{0} X_{3}^{T} X_{4}^{0} X_{5}^{T} X_{6}^{T}}{\sum_{i} X_{1 i}^{0} X_{2}^{0} X_{3}^{T} X_{4}^{0} X_{5}^{T} X_{6}^{T}} \\
& \left.\cdot \frac{\sum_{i} X_{1 i}^{T} X_{2}^{0} X_{3}^{0} X_{4}^{T} X_{5}^{T} X_{6}^{T}}{\sum_{i} X_{1 i}^{0} X_{2}^{0} X_{3}^{0} X_{4}^{T} X_{5}^{T} X_{6}^{T}}\right]^{1 / 60} \\
& \cdot\left[\frac{\sum_{i} X_{1 i}^{T} X_{2}^{T} X_{3}^{T} X_{4}^{T} X_{5}^{T} X_{6}^{0}}{\sum_{i} X_{1 i}^{0} X_{2}^{T} X_{3}^{T} X_{4}^{T} X_{5}^{T} X_{6}^{0}} \cdot \frac{\sum_{i} X_{1 i}^{T} X_{2}^{T} X_{3}^{T} X_{4}^{T} X_{5}^{0} X_{6}^{T}}{\sum_{i} X_{1 i}^{0} X_{2}^{T} X_{3}^{T} X_{4}^{T} X_{5}^{0} X_{6}^{T}}\right. \\
& \frac{\sum_{i} X_{1 i}^{T} X_{2}^{T} X_{3}^{T} X_{4}^{0} X_{5}^{T} X_{6}^{T}}{\sum_{i} X_{1 i}^{0} X_{2}^{T} X_{3}^{T} X_{4}^{0} X_{5}^{T} X_{6}^{T}} \cdot \frac{\sum_{i} X_{1 i}^{T} X_{2}^{T} X_{3}^{0} X_{4}^{T} X_{5}^{T} X_{6}^{T}}{\sum_{i} X_{1 i}^{0} X_{2}^{T} X_{3}^{0} X_{4}^{T} X_{5}^{T} X_{6}^{T}} \\
& \left.\frac{\sum_{i} X_{1 i}^{T} X_{2}^{0} X_{3}^{T} X_{4}^{T} X_{5}^{T} X_{6}^{T}}{\sum_{i} X_{1 i}^{0} X_{2}^{0} X_{3}^{T} X_{4}^{T} X_{5}^{T} X_{6}^{T}}\right]^{1 / 30} \\
& \cdot\left[\frac{\sum_{i} X_{1 i}^{T} X_{2}^{T} X_{3}^{T} X_{4}^{T} X_{5}^{T} X_{6}^{T}}{\sum_{i} X_{1 i}^{0} X_{2}^{T} X_{3}^{T} X_{4}^{T} X_{5}^{T} X_{6}^{T}}\right]^{1 / 6} \text {. }
\end{aligned}
$$

$D_{X_{1}}, D_{X_{2}}, D_{X_{3}}, D_{X_{4}}, D_{X_{5}}$, and $D_{X_{6}}$ can be derived by the calculation according to formula (7).

On the basis of different methods of data processing, the index decomposition method can be divided into a periodwise decomposition method and a time-series decomposition method. Period-wise decomposition decomposes the change of variables between two benchmark years without considering changes in the middle years. The time-series decomposition method refers to the decomposition by year $t$ and year $t+1$. In this paper, time-series decomposition is selected.

\section{Data Sources and Processing}

3.1. Data Sources. The sample period is from 1995 to 2015. The energy data of urban and rural residents are from 1996-2016 "China Energy Statistical Yearbook." The selection of energy types refers to "Chinese Energy Statistics Yearbook." Energy consumption types of urban residents include coal, coke oven gas, gasoline, kerosene, diesel oil, liquefied petroleum gas, natural gas, heat, and power. The energy consumption of gasoline, natural gas, heat, and electricity consumption increased year by year, accounting for $90 \%$ of current consumption, while coal consumption decreased significantly, and kerosene, diesel, and coke oven gas consumption are small. Compared with urban residents, the energy types of rural residents are less numerous. Coal and electricity account for more than $90 \%$ of the total energy consumption. To facilitate the comparison between urban and rural residents, coal, coke oven gas, gasoline, kerosene, diesel oil, liquefied petroleum gas, natural gas, heat, and power are selected. To ensure the comparability of data, various energy sources are translated into standard coal according to the standard coal coefficient, which is derived from the "2015 China Energy Statistical Yearbook." The $\mathrm{CO}_{2}$ emission coefficients are correspondingly expressed by the formation of standard coal. The carbon emission factors of different energy types in the coefficient transformation process are from "Guidelines for the Compilation of Provincial Greenhouse Gas Inventory." The data on consumer expenses, residential disposable income, and urban and rural population are from the previous "Beijing Statistical Yearbook." To eliminate the impact of price fluctuation, consumer spending and disposable income were converted into 1995 values, according to the consumer price index. To facilitate international comparisons, expenditures and revenues are expressed in United States dollars, using the average annual exchange rates.

3.2. Heat and Power Treatment. As the major secondary form of energy, heat and power do not produce $\mathrm{CO}_{2}$ emissions in end-use. Because $\mathrm{CO}_{2}$ emissions from power mainly come from thermal power, $\mathrm{CO}_{2}$ emissions can be determined based on the investment in producing and transforming heat and thermal power, and then the emission coefficients are calculated. Specific steps are as follows.

First, according to formula (1), the $\mathrm{CO}_{2}$ emissions from heat and thermal power in the process of conversion were calculated.

Second, $\mathrm{CO}_{2}$ emission factors can be obtained based on the calculated $\mathrm{CO}_{2}$ emissions divided by heat and power consumption (Table 1). There are two criteria to calculate $\mathrm{CO}_{2}$ emissions: the producer principle and the consumer principle. The producer principle refers to the calculation of $\mathrm{CO}_{2}$ emissions in accordance with energy input in the local production process; the consumer principle refers to the calculation of $\mathrm{CO}_{2}$ emissions according to terminal consumption. Our goal is to accurately calculate $\mathrm{CO}_{2}$ emissions in Beijing, and it does not involve the determination of the emission liability. Therefore, we take the producer principle. Because a considerable portion of Beijing's power comes from 
TABLE 1: $\mathrm{CO}_{2}$ emission coefficients of heat and power.

\begin{tabular}{lcc}
\hline Year & Heat $(\mathrm{kg} / \mathrm{MJ})$ & Power $(\mathrm{kg} / \mathrm{kW} \cdot \mathrm{h})$ \\
\hline 1995 & 0.10 & 0.51 \\
1996 & 0.10 & 0.50 \\
1997 & 0.09 & 0.44 \\
1998 & 0.08 & 0.44 \\
1999 & 0.08 & 0.42 \\
2000 & 0.08 & 0.42 \\
2001 & 0.10 & 0.40 \\
2002 & 0.10 & 0.38 \\
2003 & 0.09 & 0.37 \\
2004 & 0.10 & 0.40 \\
2005 & 0.09 & 0.37 \\
2006 & 0.10 & 0.32 \\
2007 & 0.10 & 0.29 \\
2008 & 0.10 & 0.28 \\
2009 & 0.09 & 0.24 \\
2010 & 0.09 & 0.23 \\
2011 & 0.08 & 0.21 \\
2012 & 0.09 & 0.20 \\
2013 & 0.09 & 0.22 \\
2014 & 0.08 & 0.21 \\
2015 & 0.07 & 0.18 \\
\hline
\end{tabular}

other Chinese provinces, it is not surprising that the $\mathrm{CO}_{2}$ emission coefficients are lower than the national average.

Finally, we calculate the carbon content per unit calorific value according to formula (1) and the net calorific value of heat and power and then obtain the $\mathrm{CO}_{2}$ emission coefficients expressed by the standard coal. The calorific value of $1 \mathrm{~kg}$ of standard coal is $29,271.2 \mathrm{~kJ}$.

\section{Results}

4.1. Change of Residential $\mathrm{CO}_{2}$ Emissions. Figure 1 shows that the total direct residential energy-related $\mathrm{CO}_{2}$ emissions in Beijing increased from 10.94 million tons in 1995 to 24.45 million tons in 2015, and the average growth rate is $4.1 \%$. Urban population is more important than rural population, and direct energy consumption of urban residents is also larger. The urban residents' $\mathrm{CO}_{2}$ emissions rose greatly, increasing from 7.07 million tons in 1995 to 20.29 million tons by 1.87 times. By contrast, the $\mathrm{CO}_{2}$ emissions of rural residents only rose slightly, from 3.87 million tons to 4.15 million tons.

4.2. Decomposition Analysis on Impact Factors of Residential $\mathrm{CO}_{2}$ Emissions. The decomposition results for the factors affecting urban and rural residential $\mathrm{CO}_{2}$ emissions from energy consumption in the above formulas are shown in Tables 2 and 3 and Figures 2 and 3.

Annual decomposition effect indicates the change characteristics of neighboring years. A value greater than 1 indicates that the decomposition factor plays a role in promoting $\mathrm{CO}_{2}$ emissions. The larger the value, the stronger the promoting

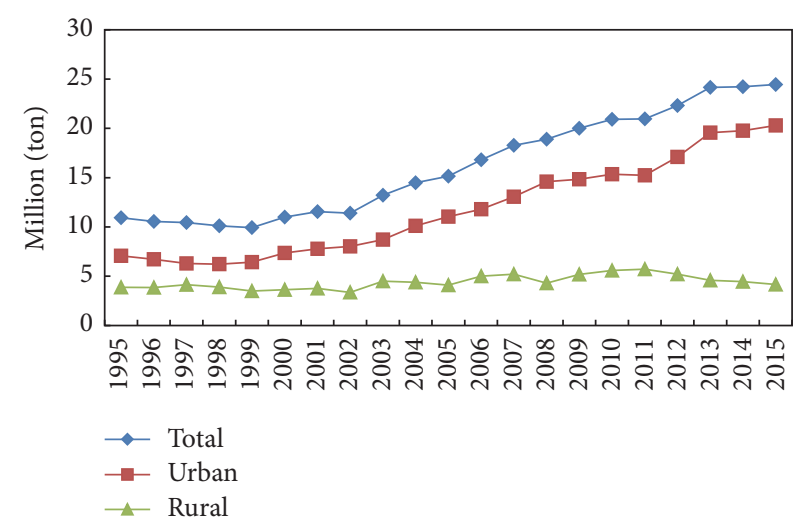

FIGURE 1: Residential energy-related $\mathrm{CO}_{2}$ emissions in Beijing from 1995 to 2015.

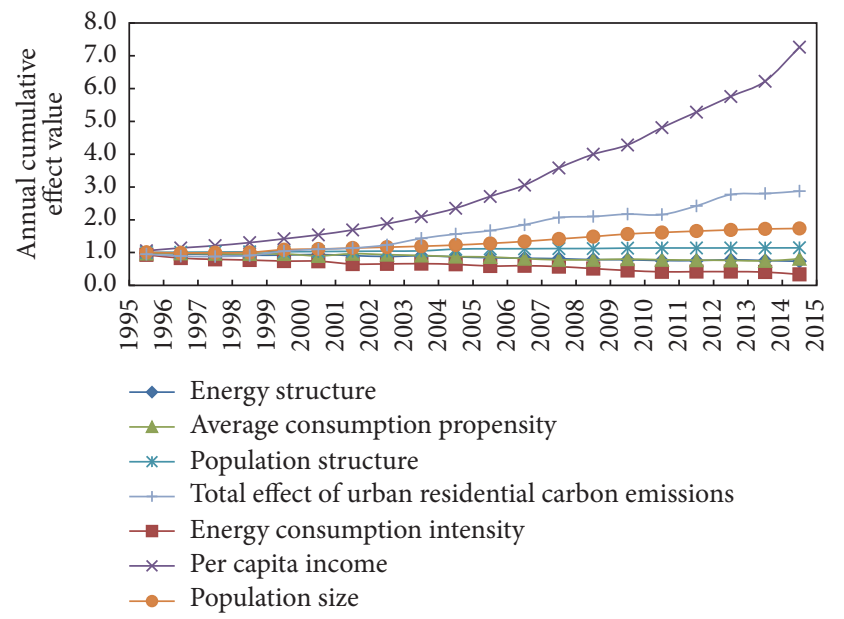

FIGURE 2: Effect of various factors on urban residential $\mathrm{CO}_{2}$ emissions in Beijing from 1995 to 2015.

effect. Value less than 1 indicates that the decomposition factor plays a role in inhibiting $\mathrm{CO}_{2}$ emissions. The smaller the value, the stronger the inhibitory effect. The cumulative effect value reflects the cumulative change from the base year to the target year.

The cumulative effect of $\mathrm{CO}_{2}$ emissions from urban and rural residents can reflect the trend of total residential $\mathrm{CO}_{2}$ emissions. As observed from Figure 1, total urban residential $\mathrm{CO}_{2}$ emissions from 1995 to 1999 were relatively stable or even declined slightly but then increased rapidly after 1999 . According to our calculations, the average annual increase is 7.46\% during 1999-2015. The changes in the rural residential $\mathrm{CO}_{2}$ emissions shown in Figure 3 are volatile. Figure 3 shows a slight downward trend in 1995-2002, an upward but fluctuating trend in 2002-2011, and a significant decrease after 2011.

As shown in Table 2 and Figure 2, per capita disposable income, population structure, and population size play positive roles in changing urban residential $\mathrm{CO}_{2}$ emissions (their cumulative effect values are greater than 1 ). Per capita 
TABLE 2: Annual decomposition effect of urban residential $\mathrm{CO}_{2}$ emissions in Beijing.

\begin{tabular}{|c|c|c|c|c|c|c|c|}
\hline Year & $D_{X_{1}}$ & $D_{X_{2}}$ & $D_{X_{3}}$ & $D_{X_{4}}$ & $D_{X_{5}}$ & $D_{X_{6}}$ & $V$ \\
\hline 1995-1996 & 0.981 & 0.932 & 0.973 & 1.056 & 1.006 & 1.007 & 0.951 \\
\hline $1996-1997$ & 0.978 & 0.892 & 1.005 & 1.081 & 1.005 & 0.985 & 0.938 \\
\hline 1997-1998 & 0.981 & 0.955 & 0.984 & 1.060 & 1.005 & 1.005 & 0.987 \\
\hline 1998-1999 & 0.978 & 0.972 & 0.992 & 1.078 & 1.005 & 1.009 & 1.032 \\
\hline $1999-2000$ & 1.002 & 0.960 & 1.005 & 1.089 & 1.003 & 1.085 & 1.146 \\
\hline $2000-2001$ & 1.022 & 0.995 & 0.939 & 1.085 & 1.007 & 1.016 & 1.059 \\
\hline 2001-2002 & 0.962 & 0.883 & 1.071 & 1.096 & 1.006 & 1.028 & 1.031 \\
\hline $2002-2003$ & 0.971 & 1.005 & 0.971 & 1.112 & 1.006 & 1.023 & 1.085 \\
\hline 2003-2004 & 1.024 & 1.012 & 0.974 & 1.115 & 1.006 & 1.025 & 1.160 \\
\hline 2004-2005 & 0.963 & 0.969 & 0.962 & 1.124 & 1.051 & 1.030 & 1.092 \\
\hline $2005-2006$ & 0.971 & 0.920 & 0.989 & 1.153 & 1.009 & 1.041 & 1.069 \\
\hline $2006-2007$ & 0.982 & 1.016 & 0.939 & 1.127 & 1.002 & 1.047 & 1.107 \\
\hline 2007-2008 & 0.984 & 0.956 & 0.955 & 1.171 & 1.005 & 1.057 & 1.118 \\
\hline 2008-2009 & 0.964 & 0.893 & 1.005 & 1.116 & 1.001 & 1.050 & 1.016 \\
\hline $2009-2010$ & 0.996 & 0.887 & 1.025 & 1.071 & 1.011 & 1.055 & 1.034 \\
\hline 2010-2011 & 0.967 & 0.909 & 0.974 & 1.123 & 1.003 & 1.029 & 0.994 \\
\hline 2011-2012 & 0.998 & 1.013 & 0.987 & 1.098 & 1.000 & 1.025 & 1.122 \\
\hline $2012-2013$ & 1.036 & 1.001 & 0.988 & 1.091 & 1.001 & 1.022 & 1.143 \\
\hline 2013-2014 & 0.968 & 0.969 & 0.979 & 1.081 & 1.001 & 1.017 & 1.011 \\
\hline $2014-2015$ & 0.970 & 0.827 & 1.087 & 1.166 & 1.001 & 1.009 & 1.014 \\
\hline 1995-2015 & 0.734 & 0.335 & 0.810 & 7.261 & 1.144 & 1.735 & 2.839 \\
\hline
\end{tabular}

Note: $D_{X_{1}}, D_{X_{2}}, D_{X_{3}}, D_{X_{4}}, D_{X_{5}}, D_{X_{6}}$, and $V$ represent energy structure effect, energy consumption intensity effect, average consumption propensity effect, per capita income effect, population structure, population size effect, and total effect of urban residential $\mathrm{CO}_{2}$ emissions.

TABLE 3: Annual decomposition effect of rural residential $\mathrm{CO}_{2}$ emissions in Beijing.

\begin{tabular}{|c|c|c|c|c|c|c|c|}
\hline Year & $D_{X_{1}}$ & $D_{X_{2}}$ & $D_{X_{3}}$ & $D_{X_{4}}$ & $D_{X_{5}}$ & $D_{X_{6}}$ & $V$ \\
\hline $1995-1996$ & 1.002 & 1.021 & 0.983 & 0.999 & 0.982 & 1.007 & 0.994 \\
\hline 1996-1997 & 0.993 & 1.116 & 0.997 & 1.006 & 0.983 & 0.985 & 1.075 \\
\hline 1997-1998 & 1.002 & 0.925 & 0.984 & 1.047 & 0.983 & 1.005 & 0.943 \\
\hline 1998-1999 & 0.997 & 0.861 & 0.993 & 1.065 & 0.983 & 1.009 & 0.900 \\
\hline $1999-2000$ & 1.003 & 0.908 & 1.012 & 1.049 & 0.989 & 1.085 & 1.037 \\
\hline $2000-2001$ & 0.997 & 0.957 & 1.000 & 1.092 & 0.977 & 1.016 & 1.033 \\
\hline 2001-2002 & 0.998 & 0.806 & 0.974 & 1.135 & 0.977 & 1.028 & 0.894 \\
\hline $2002-2003$ & 0.995 & 1.217 & 1.002 & 1.103 & 0.977 & 1.023 & 1.337 \\
\hline $2003-2004$ & 1.014 & 0.924 & 0.951 & 1.093 & 0.977 & 1.025 & 0.975 \\
\hline 2004-2005 & 0.981 & 1.033 & 1.030 & 1.091 & 0.800 & 1.030 & 0.939 \\
\hline $2005-2006$ & 0.940 & 1.165 & 1.002 & 1.117 & 0.956 & 1.041 & 1.221 \\
\hline 2006-2007 & 0.984 & 0.883 & 1.016 & 1.135 & 0.990 & 1.047 & 1.039 \\
\hline $2007-2008$ & 1.017 & 0.676 & 0.997 & 1.171 & 0.974 & 1.057 & 0.826 \\
\hline 2008-2009 & 0.965 & 0.972 & 1.071 & 1.151 & 0.993 & 1.050 & 1.206 \\
\hline 2009-2010 & 0.977 & 1.022 & 0.999 & 1.090 & 0.937 & 1.055 & 1.075 \\
\hline 2010-2011 & 0.971 & 0.962 & 0.986 & 1.103 & 0.980 & 1.029 & 1.025 \\
\hline 2011-2012 & 1.037 & 0.804 & 0.959 & 1.107 & 1.003 & 1.025 & 0.910 \\
\hline $2012-2013$ & 1.016 & 0.760 & 1.025 & 1.098 & 0.993 & 1.022 & 0.882 \\
\hline $2013-2014$ & 0.978 & 0.924 & 0.972 & 1.095 & 0.993 & 1.017 & 0.971 \\
\hline 2014-2015 & 0.991 & 0.894 & 1.070 & 0.985 & 0.992 & 1.009 & 0.934 \\
\hline 1995-2015 & 0.870 & 0.248 & 1.014 & 5.168 & 0.554 & 1.735 & 1.074 \\
\hline
\end{tabular}

Note: $D_{X_{1}}, D_{X_{2}}, D_{X_{3}}, D_{X_{4}}, D_{X_{5}}, D_{X_{6}}$, and $V$ represent energy structure effect, energy consumption intensity effect, average consumption propensity effect, per capita income effect, population structure, population size effect, and total effect of rural residential $\mathrm{CO}_{2}$ emissions. 


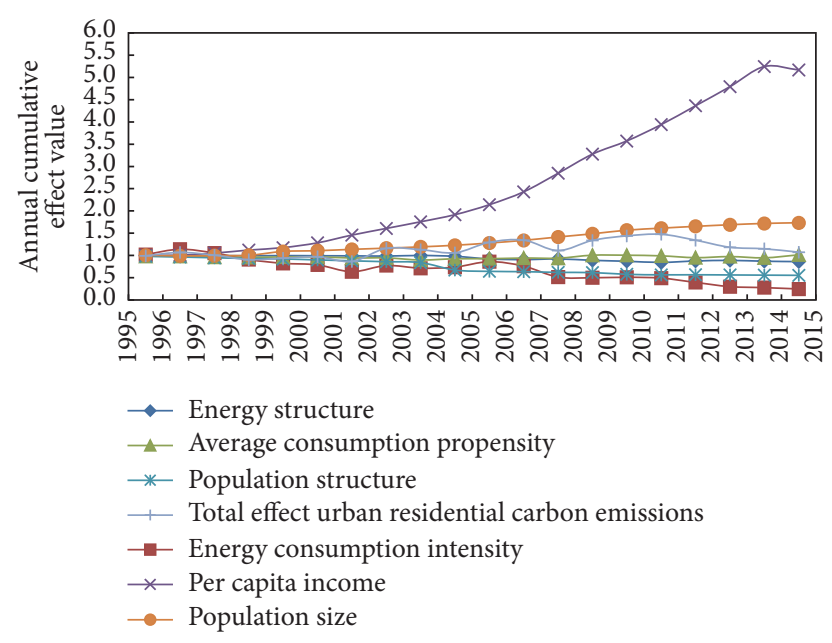

FIgURE 3: Effect of various factors on rural residential $\mathrm{CO}_{2}$ emissions in Beijing from 1995 to 2015.

disposable income is the most important factor, with a cumulative contribution value of 7.261. The degrees of influence of population structure and population size on urban residential $\mathrm{CO}_{2}$ emissions are weaker than those of per capita disposable income, with cumulative contribution values of 1.144 and 1.735. Seen from annual effect, energy consumption intensity, energy structure, and average consumption propensity show inhibitory effects on urban residential $\mathrm{CO}_{2}$ emissions during the study period, but the inhibition effects are not always present. Energy consumption intensity had a positive impact on urban residential $\mathrm{CO}_{2}$ emissions from 2002-2004, 20062007, and 2011-2013, while the influence in other years was negative. Its cumulative effect value decreased from 0.932 in 1995 to 0.335 in 2015, and it is the most important inhibition factor. The impact of energy structure fluctuated with time, similar to energy consumption intensity. It played a promoting role between 1999-2001, 2003-2004, and 20122013 , and the influence in other years was negative. Because there were more years of inhibition than years of promotion, energy structure ultimately played a role in reducing urban residential $\mathrm{CO}_{2}$ emissions. Average consumption propensity can be roughly divided into two stages. From 1995 to 2002, inhibition and promotion effects appeared alternately; thus, the impact of average consumption propensity on urban residential $\mathrm{CO}_{2}$ emissions was stable. However, it generally played an inhibiting role after 2002.

The direction and contribution of each factor to rural residential $\mathrm{CO}_{2}$ emissions are shown in Table 3 and Figure 3. Per capita disposable income and population size play a positive role in promoting rural residential $\mathrm{CO}_{2}$ emissions. As in urban areas, per capita disposable income was the dominant factor in pulling the growth of rural residential $\mathrm{CO}_{2}$ emissions during the study period, followed by population size. Their cumulative contribution values are 5.168 and 1.735 , respectively. Energy structure, energy consumption intensity, and population structure inhibited the growth of rural residential $\mathrm{CO}_{2}$ emissions. Energy consumption intensity was the most important factor, the inhibition effect of which was

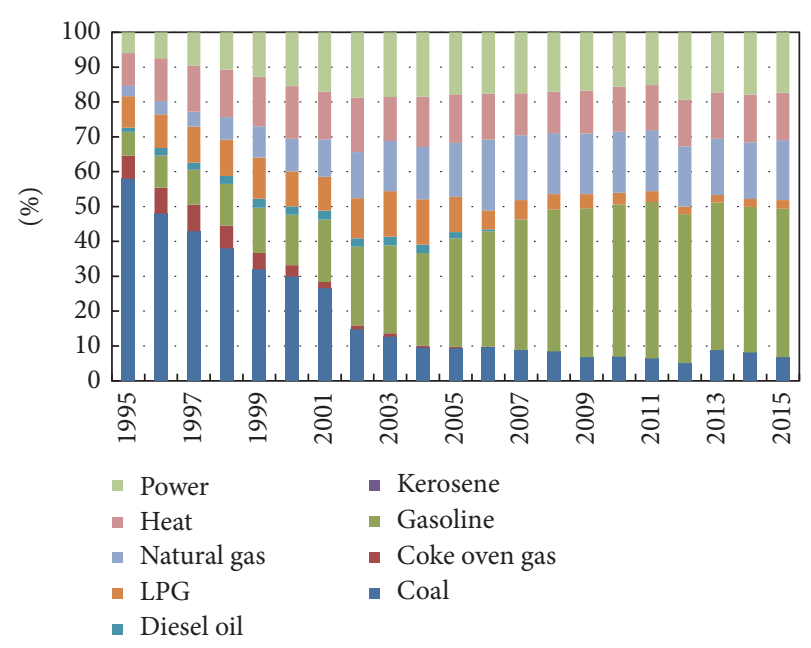

Figure 4: Proportion of various energy consumption from urban residents in Beijing from 1995 to 2015.

much greater than that of the other factors. Considering the annual effect value, energy consumption intensity had a pulling effect on rural residential $\mathrm{CO}_{2}$ emissions during 1995-1997, 2002-2003, 2004-2006, and 2009-2010, while it played a negative role during the other periods. Energy structure had a significant impact on rural residential $\mathrm{CO}_{2}$ emissions before 2004 but showed an inhibiting effect after 2004. This inhibition exhibited a strengthening trend. Population structure had a mitigating effect on rural residential $\mathrm{CO}_{2}$ emissions, which has become the second factor, behind energy consumption intensity. The impact of average consumption propensity on rural residential $\mathrm{CO}_{2}$ emissions was unique for its obvious but small fluctuations during different historical stages. It played neither a promoting role nor an inhibitory one in rural residential $\mathrm{CO}_{2}$ emissions.

\section{Discussion}

The above estimation results suggest that the impact of various factors on changing residential $\mathrm{CO}_{2}$ emissions in Beijing was different and varied with time. Effects of each factor are discussed and compared to previous studies in the next sections.

5.1. Energy Structure. Energy structure plays an inhibitory role in residential $\mathrm{CO}_{2}$ emissions, which is consistent with results for China [11, 22] but differs from the analysis of Wang et al. [15]. Changes in energy structure can inhibit the growth of direct residential $\mathrm{CO}_{2}$ emissions, reflecting the continuous structure optimization of residential energy consumption. This structural change mainly reflected the increased consumption of clean fossil energy and heat and power. As shown in Figure 4, from 1995 to 2015, the proportion of coal consumption significantly dropped from $58.00 \%$ to $6.82 \%$, while the proportion of gasoline consumption increased significantly from $6.77 \%$ to $42.54 \%$. The proportion of clean energy consumption (such as natural gas, heat, and power) gradually increased from $18.30 \%$ to $48.13 \%$. Figure 5 shows 


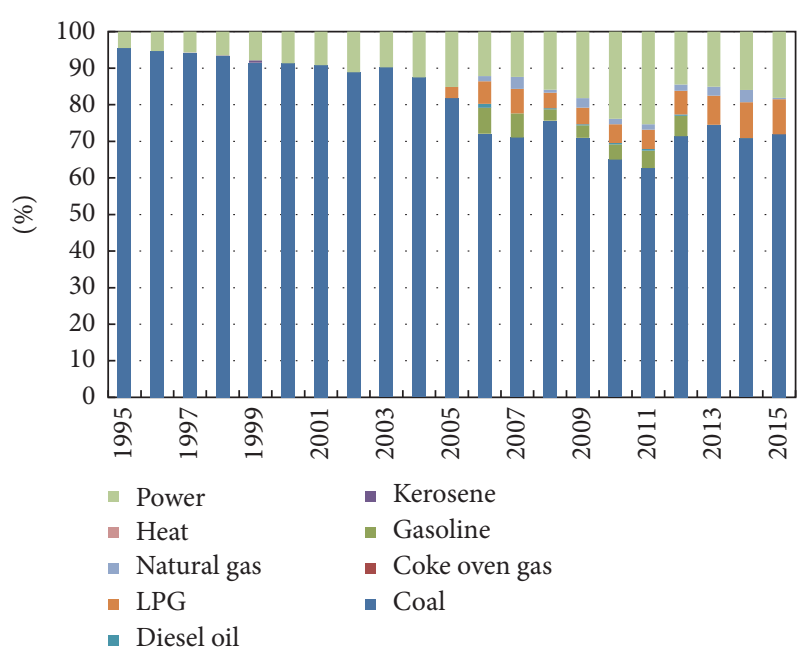

FIGURE 5: Proportion of various energy consumption from rural residents in Beijing from 1995 to 2015.

the trend in the proportionate use of various energy forms by rural residents. Before 2004, the energy consumption of rural residents was mainly concentrated in coal and power. While coal use had the absolute advantage, the increase in power was limited. Therefore, the inhibition effect of energy structure on rural residential $\mathrm{CO}_{2}$ emissions was very small. Since 2004, with the improvement of living standards, types of energy consumption gradually diversified. The proportion of coal consumption dropped from $87.46 \%$ in 2004 to $71.94 \%$ in 2015 , down to a minimum of $62.66 \%$ in 2011 , while the consumption ratio of liquefied petroleum gas, natural gas, and power increased gradually. However, the proportion of coal consumption by rural residents is currently still large, accounting for more than $60 \%$, compared to urban residents who use coal less than $10 \%$ of total energy consumption. Therefore, the inhibition effect of energy structure on urban residential $\mathrm{CO}_{2}$ emissions was stronger than that on rural residential $\mathrm{CO}_{2}$ emissions. This also means that rural residents' energy structures still have much room for further lowcarbonization adjustment.

5.2. Energy Consumption Intensity. Energy consumption intensity presents obvious negative effects on residential $\mathrm{CO}_{2}$ emissions. This finding meets our expectations and is consistent with the conclusions of most scholars. However, it is different from research on China conducted by Wang and Yang [18]. Wang and Yang [18] argued that a decrease in energy intensity among urban residents cannot compensate for increased $\mathrm{CO}_{2}$ emissions caused by consumption, resulting in the rise of an energy ecological footprint (EEF), while energy intensity can suppress the rise of the EEF for rural residents. Analysis here proves that energy consumption intensity is the primary factor influencing $\mathrm{CO}_{2}$ emissions from daily living consumption for both urban residents and rural residents. Figure 6 shows that the energy intensity of residents in Beijing decreased significantly from 1995 to 2015, with the annual average energy intensity of urban and rural

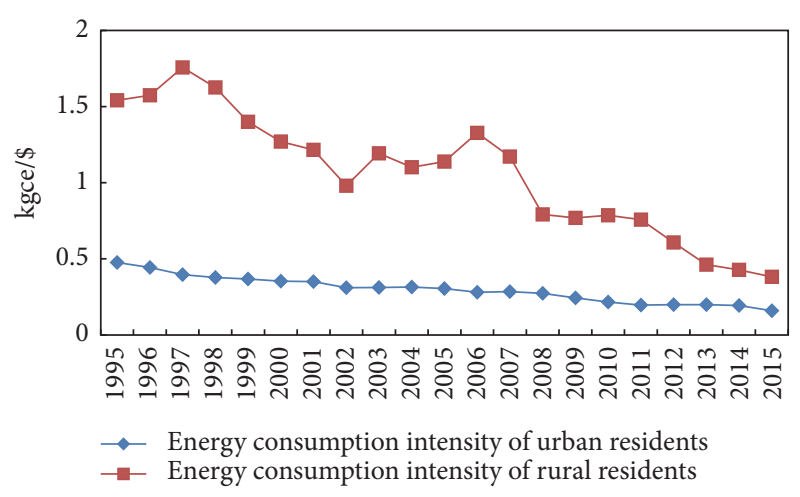

FIGURE 6: Energy consumption intensity of residents in Beijing from 1995 to 2015.

residents falling by $5.32 \%$ and $6.74 \%$, respectively. During this time, the energy consumption intensity of rural residents had a role of more inhibition on $\mathrm{CO}_{2}$ emissions than that of urban residents. In this study, declining energy intensity may be affected by two factors. One is technological progress. The magnitude of energy intensity is mainly decided by production technology, which improves energy use efficiency and helps to reduce energy consumption intensity. The other factor is energy prices. Rising energy prices make people reduce energy consumption by changing their lifestyles and consumption habits, in turn helping to reduce residential energy consumption and $\mathrm{CO}_{2}$ emissions. In recent years, as the government has implemented the "Residential Tiered Pricing Plan for Power" and "Residential Tiered Pricing Plan for Gas," the lever effects of power and gas pricing on energy consumption have been strengthened. The policy of reducing residential power and gas consumption by setting up the tiered pricing mechanism of "user pays" raises public awareness of energy conservation and emissions reduction, encouraging the habit of energy saving [11]. Because the income levels of rural residents are lower than those of residents of cities and towns, rural residents are particularly sensitive to energy prices. With relatively uniform rural energy use, the inhibitory effect of energy consumption intensity on rural residents' $\mathrm{CO}_{2}$ emissions is greater than in urban areas, due to the slower growth of energy consumption. This inhibitory effect is also magnified by the far lower growth rate of energy consumption in proportion to growth in consumption.

5.3. Average Consumption Propensity. Decomposition results show that the average consumption propensity of urban residents has a negative effect on $\mathrm{CO}_{2}$ emissions, indicating that the reduction of average consumption propensity of urban residents restrains the growth of urban residential $\mathrm{CO}_{2}$ emissions. In contrast, the average consumption propensity of rural residents tends to have little effect on their $\mathrm{CO}_{2}$ emissions, meaning that the average consumption propensity of rural residents does not play a role in inhibiting the growth of $\mathrm{CO}_{2}$ emissions. This is partly consistent with the 
situation of Guangzhou. Changes in the average consumption propensity of urban residents showed a stepwise decreasing trend and show a reduction effect on $\mathrm{CO}_{2}$ emissions. Simultaneously, the average consumption propensity of rural residents showed a trend of decline-rise-decline, ultimately playing an inhibiting role in $\mathrm{CO}_{2}$ emissions in Guangzhou [20]. Wang et al. [20] noted that this is because the social security system in China is inadequate and the formation of consumer expectations is not stable, leading residents' average consumption propensity to decline. We acknowledge the impact of this social-economic environment on residents' $\mathrm{CO}_{2}$ emissions. There still exist differences between the average consumption propensity of urban and rural residents in Beijing. According to our analysis, consumer spending from urban residents increased with the growth of income level, but the increase rate was less than the rate of income growth so that average consumption propensity had declined. This result is consistent with consumption psychology. As technology advances, the proportion of energy consumption expenditure in household consumption expenditure will decline based on the more efficient energy consumption of household products and the optimization of energy consumption structures, thus inhibiting an increase in energy consumption. Ultimately, this process plays an energy-saving and emission-reducing role. However, compared with urban residents, rural residents' income and its growth rate were both slow. The ratio of spontaneous consumption for basic life in rural residential income was relatively large, and energy consumption was mainly required to meet the needs of rigid demand. Thus, the average consumption propensity had little effect on rural residential $\mathrm{CO}_{2}$ emissions.

5.4. Per Capita Disposable Income. Per capita disposable income was the largest driving factor for stimulating the growth of urban and rural residential $\mathrm{CO}_{2}$ emissions. Compared with rural residents, the pulling effect of per capita disposable income for urban residents was stronger, indicating that the improvement of per capita disposable income for urban residents will significantly promote the growth of urban residential $\mathrm{CO}_{2}$ emissions. This is mainly owing to the large gap between urban residents' income and rural residents' income. This finding differs from those of $\mathrm{Li}$ (2013), who argues that increasing the income of rural residents in China helps to inhibit the growth of $\mathrm{CO}_{2}$ emissions. As shown in Figure 7, from 1995 to 2015, the per capita disposable income of urban and rural residents increased by 6.26 times and 4.17 times, respectively. The average annual growth rate of urban residents' per capita disposable income is $10.42 \%$, which is $1.86 \%$ faster than the growth rate of rural residents' per capita disposable income. With income growth and the improvement of living standards, residents often increase the demand for motor vehicles, home appliances, and other consumer goods to obtain more comfortable and convenient living conditions. These items consume more energy, leading to an increase in $\mathrm{CO}_{2}$ emissions. The per capita income of urban residents is growing faster, and the consumption demand for nonmaterial products is stronger, so the pulling effect on residential $\mathrm{CO}_{2}$ emissions is greater.

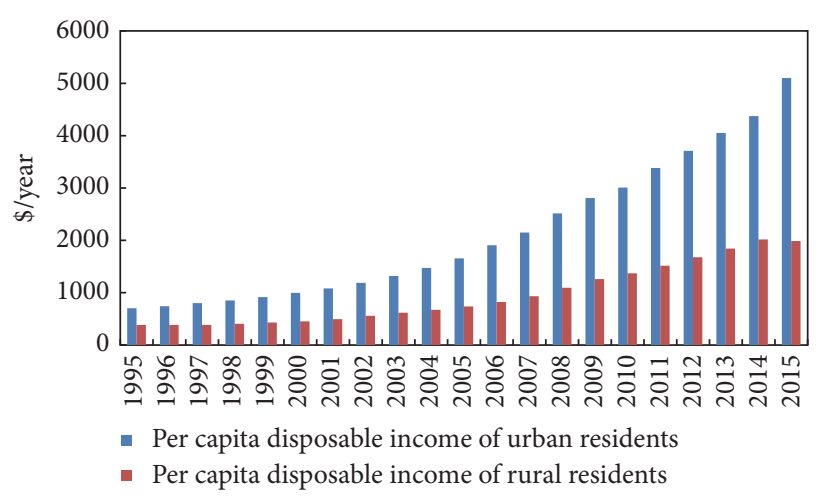

Figure 7: Per capita disposable income of urban and rural residents in Beijing from 1995 to 2015.

5.5. Population Structure. Decomposition results show that urban population structure plays a pulling effect on the growth of urban residential $\mathrm{CO}_{2}$ emissions, while rural population structure plays an inhibiting effect on the growth of rural residential $\mathrm{CO}_{2}$ emissions. These results suggest that population migration from rural to urban areas in the urbanization process will, to a certain extent, promote residential $\mathrm{CO}_{2}$ emissions in Beijing. This is similar to the situations of China $[15,23]$ and Shanghai [21]. From the perspective of population structure, the process of urbanization in Beijing is accelerating, and the population urbanization rate shows a continuous upward trend. The urban population grew from 9.46 million in 1995 to 18.78 million in 2015, Additionally, the urbanization rate expressed by the proportion of urban population compared to the total population increased from $75.6 \%$ to $86.5 \%$ between 1995 and 2015. As for annual effect, the annual effect of urban population is consistent with changes in the urbanization rate, which has a stimulating effect on residential $\mathrm{CO}_{2}$ emissions generally, and with the higher rate of population urbanization, its impact on urban residential $\mathrm{CO}_{2}$ emissions is increasing. Changes in population structure change the consumption structures of urban and rural areas by affecting lifestyle and consumption, affecting both urban and rural residents' $\mathrm{CO}_{2}$ emissions. The living and consumer environments, even the income, of urban residents are superior to those of rural residents. Further, members of most urban families are of the active consumer age, which will increase household consumption expenditure (including the use of household appliance and private cars). Improvements in education levels will increase the urban residents' demand for and frequency of use of computers, home theater equipment, and other unconventional electrical appliances, promoting urban residents' $\mathrm{CO}_{2}$ emissions. When the population structure shifts to a certain extent over time, changes in the residential $\mathrm{CO}_{2}$ emissions of urban and rural residents become relatively stable [23].

5.6. Population Size. Population size is the second most important factor (following per capita income) driving the growth of residential $\mathrm{CO}_{2}$ emissions. With the increase of population comes the development problem. Consumption scale and consumption concepts will change with the process 
of urban development, leading to increased energy consumption and $\mathrm{CO}_{2}$ emissions. The stimulating effect of population size on residential $\mathrm{CO}_{2}$ emissions can be divided into two stages. The first stage, from 1995 to 1999, may have been affected by the implementation of China's one-child policy. Population growth slowed, and the stimulating effect of population size on the growth of residential $\mathrm{CO}_{2}$ emissions was small. The second stage was from 2000 to 2015 . The rapid development of urbanization attracted a large inflow of talent, which led to an increase in household energy consumption. In turn, the stimulating effect of population size on residential $\mathrm{CO}_{2}$ emissions gradually strengthened. With the implementation of more stringent population control policy in Beijing, the impact of population size on residential $\mathrm{CO}_{2}$ emissions will be weakened.

\section{Conclusions and Policy Suggestions}

6.1. Conclusions. There are important differences in total energy consumption and energy consumption structure between urban and rural families, due to the urban-rural dual economic structure and regional differences in living habits. The study adopts the generalized Fisher index decomposition method to establish a factor decomposition model for investigating trends in residential $\mathrm{CO}_{2}$ emissions in Beijing from 1995 to 2015, and for analyzing the impacts of energy structure, energy consumption intensity, average consumption propensity, per capita disposable income, population structure, and population size on residential $\mathrm{CO}_{2}$ emissions from energy consumption. The conclusions are as follows:

(i) Both urban and rural residential $\mathrm{CO}_{2}$ emissions in Beijing are increasing with the improvement of residents' living standards and increased energy consumption. Specifically, changes in total $\mathrm{CO}_{2}$ emissions from urban residents are relatively stable from 1995 to 1999 and increased rapidly after 1999. Changes in rural residents' $\mathrm{CO}_{2}$ emissions fluctuate, showing a slight decline in volatility, then rising again in volatility, and then decreasing.

(ii) Per capita disposable income, population structure, and population size play positive roles in changes in residential $\mathrm{CO}_{2}$ emissions. Per capita disposable income is the most important factor with a cumulative contribution value of 7.261. Energy structure, energy consumption intensity, and average consumption propensity generally exhibited inhibitory effects on urban residents' $\mathrm{CO}_{2}$ emissions in the entire study period, but this inhibition was not always present. Energy consumption intensity is the most important factor in inhibiting urban residents' $\mathrm{CO}_{2}$ emissions.

(iii) For rural residents' $\mathrm{CO}_{2}$ emissions, per capita disposable income is the dominant factor driving the growth of rural residents' $\mathrm{CO}_{2}$ emissions. The second driver is population size. Energy structure, energy consumption intensity, and population structure play inhibiting roles in rural residents' $\mathrm{CO}_{2}$ emissions. Energy consumption intensity is the most important factor, the effect of which is much larger than those of the other factors. Average consumption propensity plays neither a catalytic role nor an inhibiting role in rural residents' $\mathrm{CO}_{2}$ emissions.

6.2. Policy Suggestions. The ways of life and energy consumption structures are different in urban and rural areas, leading to differences in lifestyle and $\mathrm{CO}_{2}$ emissions. With the advancement of population growth and urbanization, the reduction of $\mathrm{CO}_{2}$ emissions arising from residents' daily energy consumption should become an important aspect of greenhouse gas emissions reduction. The aforementioned analysis results are valuable policy implications for Beijing's decision makers, and appropriate reduction policies can be proposed according to the actual local condition. The specific policy implications are as follows:

(i) According to this analysis, the optimization of residents' energy consumption structure has promoted the energy conservation and $\mathrm{CO}_{2}$ emissions reduction to a certain extent and is an important force to inhibit the increase of urban and rural residents' $\mathrm{CO}_{2}$ emissions in Beijing. However, restricted by priority of coal as resources endowment in China, coal has been a dominant energy in the energy consumption for rural residents in a long time. Beijing has been committed to achieving coal-free use in the core city and decreasing the coal combustion in the rural area, reflecting the determination of Beijing's green development in the case of excess coal production capacity. According to the main point of Beijing's energy work, the following policies are suggested to further maintain or strengthen the positive role of energy structure in inhibiting residential $\mathrm{CO}_{2}$ emissions. On the one hand, Beijing should speed up the coal fire reduction. First speed up the clean transformation of coal-fired facilities and reduce the proportion of coal in thermal power. For residential heating and cooking, implement "coal for coal" of heating boilers in urban areas, and promote the idea of "coal substitution" and "send gas to countryside" in rural areas; in doing so promote clean energy use. On the other hand, promote clean energy construction, and optimize the energy structure. Improve the capacity of gas and heat supply by optimizing the distribution of energy facilities. Speed up the development of new energy and renewable energy, and formulate power quotas from renewable energy and subsidies methods of photovoltaic power generation. It is wise to support the development of clean energy projects such as wind power, hydropower, nuclear power, biomass energy, and solar energy throughout Beijing based on local conditions. Additionally, solar energy and wind energy may be applied for home lighting, water heating, and cooking [4].

(ii) The research results indicate that the reduction of energy consumption intensity has played an important role in reducing residential $\mathrm{CO}_{2}$ emissions over the past 20 years. In the future, reducing residents' energy consumption intensity is still the 
main approach to $\mathrm{CO}_{2}$ emission reduction. Technical improvements, energy saving, and energy price reform are important measures to reduce energy consumption intensity. According to guiding ideology of energy planning in "Thirteenth Five-Year Plan," measures can be taken by the following ways: first, the government should develop economic and tax incentives to encourage investment in new energy and lowcarbon technologies from relevant enterprises and social capital, improve the comprehensive utilization of fuel efficiency by encouraging and supporting the new generation of clean coal technologies (e.g., coal gasification, liquefaction; carbon capture and sequestration), and encourage technological upgrading of gas and heating facilities to improve energy utilization and heating efficiency. Second, energy price reform is benefit for residents to save direct energy consumption, especially for rural residents who are more sensitive to prices than urban residents. Therefore, similar policies should be actively promoted. For example, the government should actively promote the price reform, promote the policy of residents' ladder gas price, and adjust the implementation of differential pricing policy. Third, upgrade the heating center of urban residents, transform the existing gas facilities in rural areas, and improve the emission reduction level of energy facilities. Since the application of energy-saving materials, green designs, and innovative energy supply systems may lower energy, water, and material consumption compared with traditional buildings [46], build low-carbon buildings according to local weather conditions and construction technologies should be encouraged.

(iii) Income growth is the main reason for the increase of residential energy consumption and related $\mathrm{CO}_{2}$ emissions. With the increased income and improved living standards, residents tend to consume more energy in exchange for more comfortable and convenient living conditions [14]. In this process, advocating an eco-friendly lifestyle is one of the most important measures to realize residents' $\mathrm{CO}_{2}$ emissions reduction. Feasible activities include improve residents' environmental protection awareness by publicity and education means such as regular workshops, communications, brochures, TV/radio promotions, and advertising; strengthen the development and use of energy-saving products and technologies; encourage residents' low-carbon consumption through fiscal and taxation policies such as carbon taxes and low-carbon cost subsidies, including subsidies and rewards for energy-efficient appliances and transportation tools; the municipal government agencies at all levels in Beijing should promote green government procurement to make a demonstration for the public and should strengthen government management and supervision to promote consumption quality and environmental protection. (iv) With the rapid advance of urbanization, many rural residents have migrated to cities. Compared to rural residents, the higher income and average energy consumption of urban residents promote a continuous growth of $\mathrm{CO}_{2}$ emissions. Therefore, energy conservation and emissions reduction policies should limit some "luxury" emissions of urban residents under the premise of guaranteeing the moderate "survival and development" emissions of rural residents and should develop targeted emission reduction measures according to the characteristics of urban and rural residents' consumption [22]. According to our analysis, gasoline consumption of urban residents rose significantly during the study period. For urban residents, $\mathrm{CO}_{2}$ emissions reduction potential may be given into full play by the development of public transportation and new energy vehicles which save petrol and diesel. For example, the government should increase the fuel tax, so that more money is to be used for research and development of highefficiency technologies and cars with energy saving or renewable energy; encourage the construction of infrastructure related to green transportation such as improved transportation network, power charging stations, and natural gas stations. In addition, reasonably control the increase of energy intensive home appliances, continue to implement energy efficiency label management, improve the energy efficiency of electric equipment with high energy consumption, and recycle all kinds of electronic wastes to reduce the use of new energy materials and $\mathrm{CO}_{2}$ emissions. In rural areas, as dependence on coal cannot decreases significantly in the short-to-medium term, it is suggested that kitchen home appliances be incorporated into the list in the policy of "home appliances delivered to the countryside" to improve the use of kitchen home appliances and reduce the usage frequency of coal by residents. To save energy for rural household heating, application of energy-saving furnaces and solar energy heating can be developed.

(v) The increase in population will put pressure on residents' carbon emissions. We can not cut the population in a short time but can continue to control the population of Beijing to reduce energy pressure. Meanwhile, combined with the work of the old city transformation in core area and population demolition, the government can continue to evacuate the urban population, promote "coal to electricity/gas" of cottage in core area, and reduce the pressure of population to $\mathrm{CO}_{2}$ emissions.

\section{Competing Interests}

The authors declare that there is no conflict of interests regarding the publication of this paper. 


\section{Acknowledgments}

The authors express sincere thanks for the financial support from China Geological Survey under Grant no. 121201103000150112, the National Natural Science Foundation of China under Grant no. 71173200, and the Development and Research Center of China Geological Survey under Grant no. 12120114056601.

\section{References}

[1] M. Chitnis and L. C. Hunt, "What drives the change in UK household energy expenditure and associated $\mathrm{CO}_{2}$ emissions? Implication and forecast to 2020," Applied Energy, vol. 94, pp. 202-214, 2012.

[2] S. Lee and B. Lee, "The influence of urban form on GHG emissions in the U.S. household sector," Energy Policy, vol. 68, pp. 534-549, 2014.

[3] A. H. Sharaai, A. M. Mokhtar, N. W. Jin, and N. A. Azali, "Determining the primary factor contributed to household carbon emission by using Structural Equation Modelling (SEM)," Procedia Environmental Sciences, vol. 30, pp. 344-348, 2015.

[4] A. Das and S. K. Paul, " $\mathrm{CO}_{2}$ emissions from household consumption in India between 1993-94 and 2006-07: a decomposition analysis," Energy Economics, vol. 41, pp. 90-105, 2014.

[5] A. C. Kerkhof, R. M. J. Benders, and H. C. Moll, "Determinants of variation in household $\mathrm{CO}_{2}$ emissions between and within countries," Energy Policy, vol. 37, no. 4, pp. 1509-1517, 2009.

[6] R. Miehe, R. Scheumann, C. M. Jones, D. M. Kammen, and M. Finkbeiner, "Regional carbon footprints of households: a German case study," Environment, Development and Sustainability, vol. 18, no. 2, pp. 577-591, 2016.

[7] L. Castellucci, A. D’Amato, and M. Zoli, "Environmental quality and income inequality: the impact of redistribution on direct household emissions in Italy," in Environmental Taxes and Fiscal Reform, pp. 123-141, Palgrave Macmillan, Basingstoke, UK, 2012.

[8] Y.-M. Wei, L.-C. Liu, Y. Fan, and G. Wu, "The impact of lifestyle on energy use and $\mathrm{CO}_{2}$ emission: an empirical analysis of China's residents," Energy Policy, vol. 35, no. 1, pp. 247-257, 2007.

[9] F. Huang and K. S. Jiang, "An analysis of the dynamic characteristics and the influential factors of carbon emissions from residential consumption in China," Systems Engineering, vol. 31, no. 1, pp. 52-60, 2013 (Chinese).

[10] H. Dai, T. Masui, Y. Matsuoka, and S. Fujimori, "The impacts of China's household consumption expenditure patterns on energy demand and carbon emissions towards 2050," Energy Policy, vol. 50, pp. 736-750, 2012.

[11] Z. Wang and X. J. Ru, " $\mathrm{CO}_{2}$ emissions induced by household consumption and its driving forces in China: an empirical analysis based on the LMDI model," Ecological Economy, vol. 31, no. 4, pp. 51-55, 2015 (Chinese).

[12] Z. Wang and L. Yang, "Indirect carbon emissions in household consumption: evidence from the urban and rural area in China," Journal of Cleaner Production, vol. 78, pp. 94-103, 2014.

[13] L.-C. Liu, G. Wu, J.-N. Wang, and Y.-M. Wei, "China's carbon emissions from urban and rural households during 1992-2007," Journal of Cleaner Production, vol. 19, no. 15, pp. 1754-1762, 2011.

[14] K. Li, "Analysis on the influencing factors of carbon emissions from urban and rural residents' living energy consumption in
China," Consumer Economics, vol. 29, no. 2, pp. 73-80, 2013 (Chinese).

[15] D. Wang, Y. J. Ji, L. L. Tian, and T. Zhu, "Study on the influencing factors of $\mathrm{CO}_{2}$ emissions from residential energy consumption in China," Environmental Pollution and Control, vol. 34, no. 4, pp. 101-105, 2012 (Chinese).

[16] Q. Zhu, X. Z. Peng, and K. Y. Wu, "Analysis on the change of the load energy carbon emissions of the residents based on the structure decomposition," The Journal of Quantitative \& Technical Economics, vol. 1, pp. 65-77, 2012 (Chinese).

[17] J. Li, X. Huang, H. Yang et al., "Situation and determinants of household carbon emissions in Northwest China," Habitat International, vol. 51, pp. 178-187, 2016.

[18] Z. Wang and Y. Yang, "Features and influencing factors of carbon emissions indicators in the perspective of residential consumption: evidence from Beijing, China," Ecological Indicators, vol. 61, pp. 634-645, 2016.

[19] G. Wu, T. Liu, and M. Tang, "Analysis of household energy consumption and related $\mathrm{CO} 2$ emissions in the disregarded villages of Lijiang City, China," International Journal of Sustainable Development and World Ecology, vol. 19, no. 6, pp. 500-505, 2012.

[20] W. Wang, D. Zhao, and Y. Kuang, "Decomposition analysis on influence factors of direct household energy-related carbon emission in Guangdong province-based on extended Kaya identity," Environmental Progress and Sustainable Energy, vol. 35, no. 1, pp. 298-307, 2016.

[21] K. Y. Wu, W. X. Wang, H. Zhang, and G. X. Wang, "Indirect carbon emissions of Shanghai's residents consumption and its influence factors," East China Economic Management, vol. 27, no. 1, pp. 1-7, 2013 (Chinese).

[22] S. J. Peng and W. C. Zhang, "An empirical analysis on the trend of carbon emissions and its influencing factors of residential consumption in China," World Economy, no. 3, pp. 124-142, 2013 (Chinese).

[23] J. S. Qu, L. N. Liu, J. J. Zeng, Z. Q. Zhang, L. Wang, and Q. H. Wang, "Ananlysis on driving factors of China's urban and rural household carbon emissions," China Population Resources and Environment, vol. 24, no. 8, pp. 33-41, 2014 (Chinese).

[24] E. Papathanasopoulou, "Household consumption, associated fossil fuel demand and carbon dioxide emissions: the case of Greece between 1990 and 2006," Energy Policy, vol. 38, no. 8, pp. 4152-4162, 2010.

[25] L. Feng, T. Lin, and Q. J. Zhao, "Analysis on the dynamic characteristics of energy consumption and carbon emissions from urban residents in China," Population, Resources and Environment, vol. 21, no. 5, pp. 93-100, 2011 (Chinese).

[26] Z.-H. Feng, L.-L. Zou, and Y.-M. Wei, "The impact of household consumption on energy use and $\mathrm{CO}_{2}$ emissions in China," Energy, vol. 36, no. 1, pp. 656-670, 2011.

[27] T. Zhao and R.-H. Cui, "Study on carbon footprint of the household consumption in Tianjin based on input-output analysis," in Proceedings of the 20th International Conference on Industrial Engineering and Engineering Management (IEEM '13), pp. 613-624, December 2013.

[28] M. N. V. Seriño and S. Klasen, "Estimation and determinants of the Philippines' household carbon footprint," Developing Economies, vol. 53, no. 1, pp. 44-62, 2015.

[29] S. Bin and H. Dowlatabadi, "Consumer lifestyle approach to US energy use and the related $\mathrm{CO}_{2}$ emissions," Energy Policy, vol. 33, no. 2, pp. 197-208, 2005. 
[30] W. Liu, G. Spaargaren, N. Heerink, A. P. J. Mol, and C. Wang, "Energy consumption practices of rural households in north China: basic characteristics and potential for low carbon development," Energy Policy, vol. 55, pp. 128-138, 2013.

[31] M. Wier, M. Lenzen, J. Munksgaard, and S. Smed, "Effects of household consumption patterns on $\mathrm{CO}_{2}$ requirements," Economic Systems Research, vol. 13, no. 3, pp. 259-274, 2001.

[32] J. Fan, X. Guo, D. Marinova, Y. Wu, and D. Zhao, "Embedded carbon footprint of Chinese urban households: structure and changes," Journal of Cleaner Production, vol. 33, pp. 50-59, 2012.

[33] J. Golley and X. Meng, "Income inequality and carbon dioxide emissions: the case of Chinese urban households," Energy Economics, vol. 34, no. 6, pp. 1864-1872, 2012.

[34] X. Z. Peng and Q. Zhu, "Analysis on the impact of China's population situation and consumption patterns on carbon emissions," Population Research, vol. 34, no. 1, pp. 48-58, 2010 (Chinese).

[35] Q. Zhu, X. Z. Peng, and Z. M. Lu, "Analysis model and empirical study on the impact of population and consumption on carbon emissions," China Population Resources and Environment, vol. 20, no. 2, pp. 98-102, 2010 (Chinese).

[36] C. Ma, "A multi-fuel, multi-sector and multi-region approach to index decomposition: an application to China's energy consumption 1995-2010," Energy Economics, vol. 42, pp. 9-16, 2014.

[37] B. W. Ang, "Sector disaggregation, structural effect and industrial energy use: an approach to analyze the interrelationships," Energy, vol. 18, no. 10, pp. 1033-1044, 1993.

[38] J.-W. Li, R. M. Shrestha, and W. K. Foell, "Structural change and energy use: the case of the manufacturing sector in Taiwan," Energy Economics, vol. 12, no. 2, pp. 109-115, 1990.

[39] S. Alam, "Efficiency of electricity consumption in Pakistan's industrial sector: an application of the multi-level decomposition model," Pacific and Asian Journal of Energy, vol. 12, no. 2, pp. 167-179, 2002.

[40] Z. Liu, Y. Geng, S. Lindner, and D. Guan, "Uncovering China's greenhouse gas emission from regional and sectoral perspectives," Energy, vol. 45, no. 1, pp. 1059-1068, 2012.

[41] S. Petrick, Carbon Efficiency, Technology, and the Role of Innovation Patterns: Evidence from German Plant-Level Microdata, Institute for the World Economy, 2013.

[42] B. W. Ang, F. L. Liu, and H.-S. Chung, "A generalized Fisher index approach to energy decomposition analysis," Energy Economics, vol. 26, no. 5, pp. 757-763, 2004.

[43] X. Y. Xu and B. W. Ang, "Multilevel index decomposition analysis: approaches and application," Energy Economics, vol. 44, pp. 375-382, 2014.

[44] H. S. Eggelston, L. Buendia, K. Miwa, T. Ngara, and K. Tanabe, Guidelines for National Greenhouse Gas Inventories, IPCC National Greenhouse Gas Inventories Programme, Hayama, Japan, 2006.

[45] F. Fan and Y. Lei, "Decomposition analysis of energy-related carbon emissions from the transportation sector in Beijing," Transportation Research Part D: Transport and Environment, vol. 42, pp. 135-145, 2016.

[46] X. Tian, Y. Geng, H. Dong et al., "Regional household carbon footprint in China: a case of Liaoning province," Journal of Cleaner Production, vol. 114, pp. 401-411, 2016. 


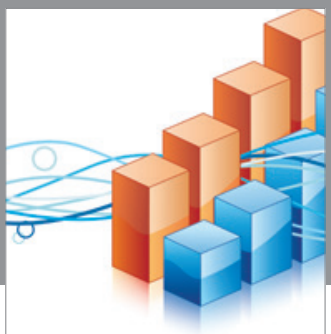

Advances in

Operations Research

vatem alat4

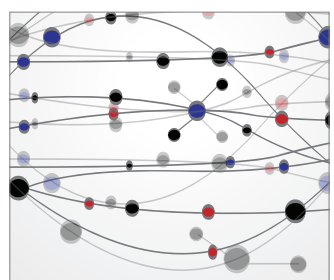

\section{The Scientific} World Journal
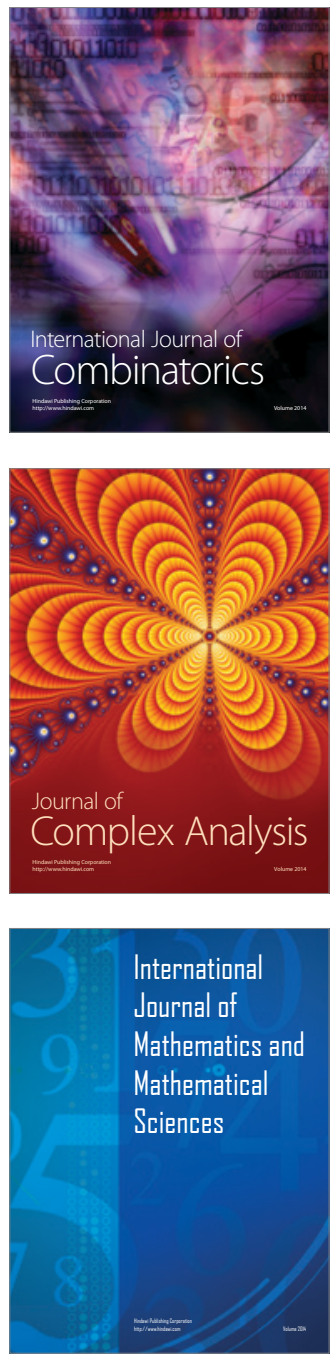
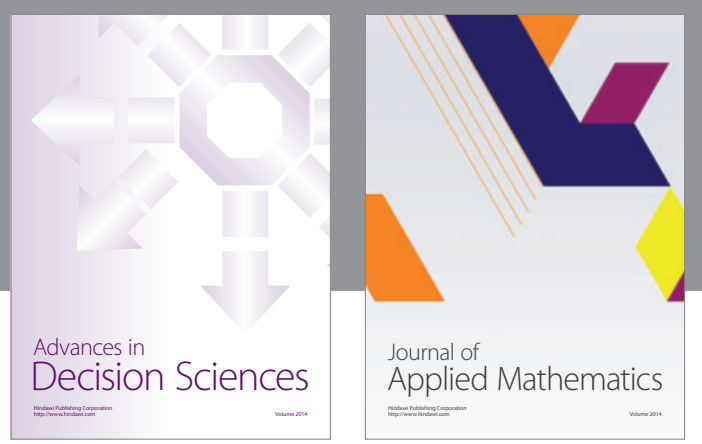

Algebra

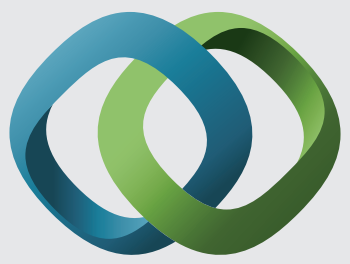

\section{Hindawi}

Submit your manuscripts at

https://www.hindawi.com
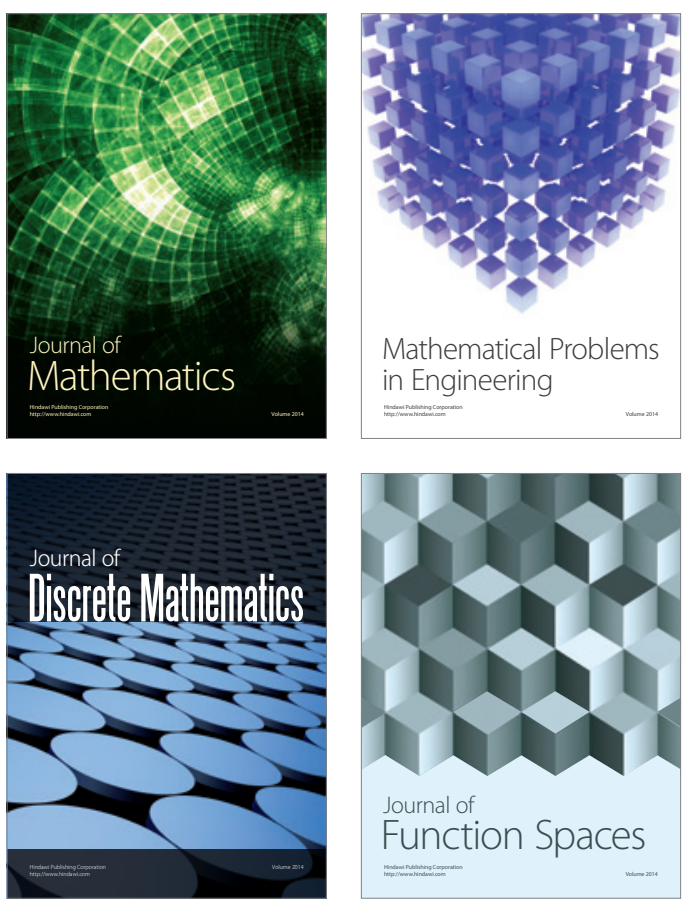

Mathematical Problems in Engineering
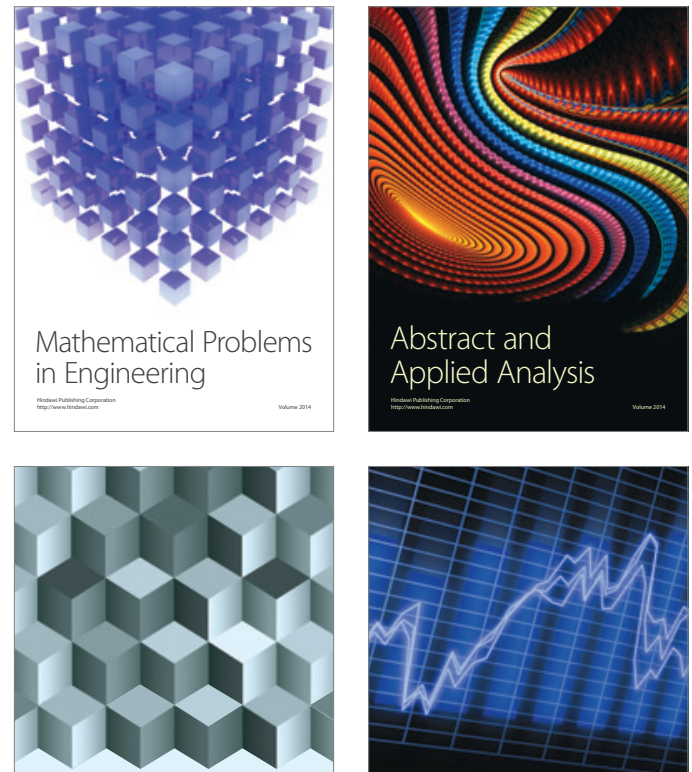

Journal of

Function Spaces

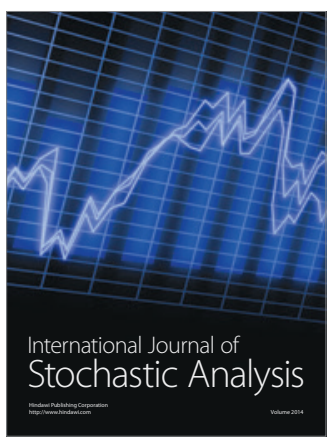

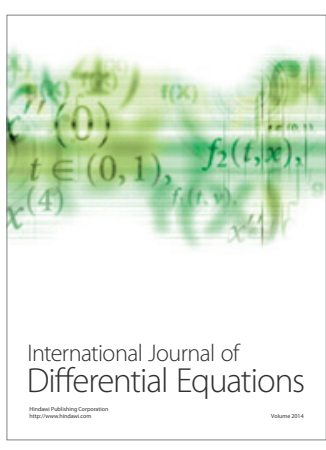
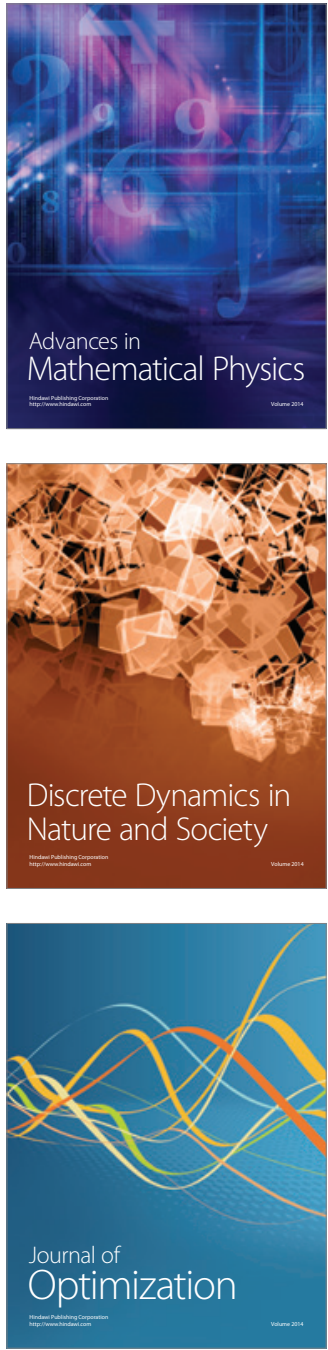